Vol. 25, n. 1, 2020.

\title{
EDUCACIÓN AMBIENTAL DESDE EL SER PARA EL BUEN VIVIR: ¿POR QUÉ LA ORTIGA IRRITA LA PIEL?
}

\author{
EDUCAÇÃO AMBIENTAL DO SER PARA A BOA VIDA: \\ Por que a urtiga irrita a pele?
}

\section{ENVIRONMENTAL EDUCATION FROM THE BEING AND TO THE GOOD LIVING: Why does the nettle irritate the skin?}

\author{
Mónica Alejandra Pachón Solano ${ }^{1}$
}

\section{RESUMEN}

La Educación Ambiental debe ser un proceso de formación para la ciudadanía desde el ser, su autoconocimiento y la autodefinición promueve actitudes y hábitos hacia el buen vivir en equilibrio con la vida, en este sentido, la propuesta desarrollada por estudiantes de quinto grado del Colegio Tomas Carrasquilla I.E.D (Bogotá-Colombia) alrededor de la problemática ¿Por qué la ortiga irrita la piel? enmarca un proyecto de investigación escolar que resignifica el saber popular (prácticas culturales)-científico (ácidos, taxonomía, vitaminas, minerales)-ancestral (cosmovisión, prácticas y propiedades medicinales) en torno al estudio de esta planta en el contexto de educación primaria en Colombia, que transforme la relación con el otro y el entorno, a través del saber ambiental como un dialogo de saberes, sin verdades fragmentadas, sino como procesos colaborativos de construcción social, en el que la relación del hombre y el ambiente no es jerárquica sino de coexistencia, partiendo de la racionalidad ambiental (Leff, 2012).

Palabras Clave: Dialogo de saberes, Racionalidad Ambiental, Educación Ambiental, ser.

\footnotetext{
${ }^{1}$ Licenciada en Química, Universidad Pedagógica Nacional. Magister en Docencia de la Química, Universidad Pedagógica Nacional. Correo: mapachons@upn.edu.co-mapachons@educacionbogota.edu.co
} 


\section{RESUMO}

A educação ambiental deve ser um processo de formação da cidadania, seu autoconhecimento e autodefinição promovem atitudes e hábitos em relação ao bem viver em equilíbrio com a vida, nesse sentido, a proposta desenvolvida pelos alunos da quinta série do Tomas College Carrasquilla IED (Bogotá-Colômbia) em torno do problema Por que a urtiga irrita a pele? enquadra um projeto de pesquisa escolar que ressignifica o conhecimento popular (práticas culturais) - científico (ácidos, taxonomia, vitaminas, minerais) - anestésico (visão de mundo, práticas e propriedades medicinais) em torno do estudo dessa planta no contexto da educação primária em Colômbia, que transforma a relação com o outro e o meio ambiente, através do conhecimento ambiental como um diálogo do conhecimento, sem verdades fragmentadas, mas como processos colaborativos de construção social, nos quais a relação do homem e do meio ambiente não é hierárquica, mas de coexistência, com base na racionalidade ambiental (Leff, 2012).

Palavras Chave: Diálogo sobre conhecimento, Racionalidade ambiental, Educação ambiental, ser.

\section{ABSTRACT}

Environmental Education must be a process of formation for citizenship from being, their self-knowledge and self-definition promotes attitudes and habits towards good living in balance with life, in this sense, the proposal developed by fifth grade students of the Tomas College Carrasquilla IED (Bogotá-Colombia) around the problem Why does nettle irritate the skin? frames a school research project that resignifies popular knowledge (cultural practices) -scientific (acids, taxonomy, vitamins, minerals) -ancestral (worldview, practices and medicinal properties) around the study of this plant in the context of primary education in Colombia, which transforms the relationship with the other and the environment, through environmental knowledge as a dialogue of knowledge, without fragmented truths, but as collaborative processes of social construction, in which the relationship of man and the environment is not hierarchical but of coexistence, based on environmental rationality (Leff, 2012).

Key words: Dialogue of knowledge, Environmental Rationality, Environmental Education, ser. 


\section{INTRODUCCIÓN}

La necesidad de hablar sobre educación ambiental, parte de la involución de las relaciones hombre medio, evidenciados en la transformación en el papel del ser humano como parte de la naturaleza a ser el centro de esta, considerándola como proveedora de recursos, desencadenando sobreexplotación y "produciendo cambios sustanciales e irreversibles en los mecanismos naturales" (GARCÍA Y FERRANDIS, 1990, p.5).

En este sentido se hace necesario replantear las practicas educativas desde la escuela, de tal manera que se privilegie la formación del ser como principio de una ciudadanía responsable y consciente de su papel como parte del ambiente, a partir del reconocimiento de las falencias y dificultades del saber popular para que en el contexto del conocimiento ancestral y científico se haga de la educación un estilo de vida que forme ciudadanos críticos para el buen vivir y que promueva la recuperación del equilibrio dinámico del medio.

Si bien la educación ambiental contempla las concepciones "no científicas", es importante cooperar desde diferentes áreas de conocimiento, para construir un saber ambiental, al alcance de todos, utópico pero responsable, en el que la educación sea el principal espacio de racionalidad ambiental, un espacio de conocimiento científico "en donde sean revalorizados los conocimientos naturales y los saberes populares producidos por diferentes culturas en su coevolución con la naturaleza" (LEFF,2012, p.52).

\section{EDUCACIÓN AMBIENTAL EN LATINOAMÉRICA}

Durante los últimos 50 años, la Educación ambiental ha retomado fuerza debido a la crisis en que se encuentra el mundo, luego de que el hombre dejo de ser parte del ambiente para considerarse el centro de toda la naturaleza, de tal manera que se ha quebrado el equilibrio dinámico de la misma por la sobreexplotación económica y política de los recursos, a tal punto que se acude a estudios complejos en educación ambiental, como un mecanismo de transformación social que disminuya la velocidad de degradación del planeta. 
Latinoamérica evidencia desde la década de los 60 una serie de situaciones sociales que han impactado la educación de la región, como lo expresa Gaudeano (2001, p.145) estos se basan en problemas político-militares, el rezago económico, la globalización y las variadas crisis que caracterizan el mundo en la época actual. Muchos son los eventos, en los que líderes mundiales han contemplado la educación ambiental como punto central de discusión, estableciendo objetivos, características y pautas, como las resumidas en la tabla 1, que permiten contextualizar la discusión para el país y definir el concepto de educación ambiental que enmarca la propuesta.

\begin{tabular}{|c|c|c|}
\hline AÑO & EVENTO & $\begin{array}{l}\text { APORTES A LA EDUCACIÓN } \\
\text { AMBIENTAL }\end{array}$ \\
\hline 1971 & $\begin{array}{l}\text { Consejo internacional de } \\
\text { coordinación del programa } \\
\text { sobre el hombre y la biosfera. } \\
\text { (MAB) }\end{array}$ & $\begin{array}{l}\text { Se fundamentan los conocimientos de } \\
\text { Ciencias Naturales y Ciencias sociales } \\
\text { en la relación hombre-biosfera, como } \\
\text { lo es la formación ambiental. }\end{array}$ \\
\hline 1972 & $\begin{array}{l}\text { Conferencia de las Naciones } \\
\text { Unidas sobre el Medio } \\
\text { Ambiente (Estocolmo) }\end{array}$ & $\begin{array}{l}\text { Abordaje multidisciplinar de la } \\
\text { educación ambiental en todos los } \\
\text { niveles de enseñanza. }\end{array}$ \\
\hline 1975 & $\begin{array}{l}\text { Seminario Internacional sobre } \\
\text { Educación } \\
\text { (Belgrado) }\end{array}$ & $\begin{array}{l}\text { Se establece metas y objetivos de la } \\
\text { educación ambiental, entendiendo } \\
\text { ambiente como la relación entre el } \\
\text { medio natural y artificial. }\end{array}$ \\
\hline 1976 & $\begin{array}{l}\text { Taller subregional de } \\
\text { educación ambiental para la } \\
\text { enseñanza secundaria. (Perú) }\end{array}$ & $\begin{array}{l}\text { Promueve conocimiento ligado a } \\
\text { problemas ambientales, siendo la } \\
\text { educación una actividad permanente y } \\
\text { transformadora. }\end{array}$ \\
\hline 1977 & $\begin{array}{l}\text { Conferencia } \\
\text { Intergubernamental de } \\
\text { Educación ambiental. (Tbilisi) }\end{array}$ & $\begin{array}{l}\text { Destaca la importancia de retomar } \\
\text { problemas en relación con el ambiente } \\
\text { y el desarrollo de una población, }\end{array}$ \\
\hline
\end{tabular}




\begin{tabular}{|c|c|c|}
\hline & & $\begin{array}{l}\text { reconociendo que la Educación } \\
\text { Ambiental como un factor importante } \\
\text { en la transformación política, social, } \\
\text { cultural y económica del mundo. }\end{array}$ \\
\hline 1992 & $\begin{array}{l}\text { Cumbre de Rio (Brasil) y el } \\
\text { Congreso Iberoamericano de } \\
\text { Educación Ambiental (México) }\end{array}$ & $\begin{array}{l}\text { Bren las puertas a la discusión sobre } \\
\text { educación Ambiental, catalizando el } \\
\text { fortalecimiento de iniciativas } \\
\text { ambientales atadas al currículo de } \\
\text { educación básica, creación de } \\
\text { programas académicos y organización } \\
\text { regional. }\end{array}$ \\
\hline 1994 & $\begin{array}{l}\text { Seminario taller regional sobre } \\
\text { educación e información en } \\
\text { medio ambiente, población y } \\
\text { desarrollo humano sustentable. } \\
\text { (Chile) }\end{array}$ & $\begin{array}{l}\text { Se promueve el proyecto Ambiente } \\
\text { Población y Desarrollo pretendiendo } \\
\text { cambiar el termino de educación } \\
\text { ambiental por educación para el } \\
\text { desarrollo sustentable. }\end{array}$ \\
\hline 1995 & $\begin{array}{l}\text { Reunión para América Latina } \\
\text { sobre la Gestión de Programas } \\
\text { Nacionales de Educación y } \\
\text { Capacitación para el Medio } \\
\text { Ambiente y el Desarrollo. } \\
\text { (Ecuador) }\end{array}$ & $\begin{array}{l}\text { Se consolidan propuestas } \\
\text { ejemplificantes en la región, que dieron } \\
\text { resultado a redes de colaboración } \\
\text { sobre educación ambiental. }\end{array}$ \\
\hline 1996 & $\begin{array}{l}\text { Declaración y Plan de Acción } \\
\text { para el Desarrollo Sustentable } \\
\text { de las Américas (Bolivia) }\end{array}$ & $\begin{array}{l}\text { Se hace significativo el interés por la } \\
\text { implementación de la educación } \\
\text { ambiental y la sensibilización de la } \\
\text { región por los problemas ambientales. }\end{array}$ \\
\hline
\end{tabular}

Tabla No. 1. Adaptación según García y Ferrandis, 1990. Guimarães 1995 y Gaudiano, 2001.

Fuente: Creación Propia. 
Se evidencian avances significativos en el reconocimiento de la educación ambiental en la región, enmarcados en fuertes situaciones políticas y económicas que limitaron o impulsaron el desarrollo de la disciplina, destacando el saber ambiental en los procesos educativos, dentro de los cuales se destaca "el autoritarismo y enciclopedismo del nivel básico y del superior, la concepción de educando pasivo y que por tanto no promueve la constitución de sujetos de cara a su realidad, y una realidad educativa profundamente desigual en términos de calidad y oportunidades entre escuelas públicas y privadas" (GAUDEANO, 2001, p.149).

Cabe destacar, además que, si bien los avances en materia de educación ambiental comienzan fuera del país, este hacia 1976 y como participante de los talleres subregional de educación ambiental para la enseñanza secundaria, realiza aportes en cuanto a la educación ambiental como un "elemento esencial de todo proceso de ecodesarrollo y como tal, debe proveer a los individuos y comunidades destinatarias, de las bases intelectuales, morales y técnicas" (TEITELBAUM,1998, p.51). De esta manera el país comienza a involucrarse en la educación y saber ambiental, a partir de la ley 99 de 1993 por la cual se constituye el ministerio de medio ambiente, hoy Ministerio de Medio Ambiente y desarrollo Sostenible, el cual tiene como fin fundamental, de acuerdo con la política nacional de educación ambiental SINA, expedido por el Ministerio de Educación Nacional (2002) el propiciar la aplicación de los principios generales que deben regir la política ambiental colombiana y concertar, coordinar y organizar lo relacionado con esta materia.

Se establece a la Educación ambiental como un fin de la educación, desde la Ley 115 de 1994, con el fin de prevenir desastres, mejorar la calidad de vida y el cuidar el patrimonio cultural de la Nación, posteriormente, mediante el decreto 1743 de 1994 se reglamentan los Proyectos Educativos Ambientales PRAE, contemplando elementos como la conceptualización, cualificación de docentes, servicio social ambiental obligatorio así como servicio militar ambiental, además de otros principios rectores que formen al educando en pro de la protección, preservación y aprovechamiento de los recursos naturales y el mejoramiento de 
las condiciones humanas y del ambiente en las instituciones educativas del país, los cuales para finalmente desarrollar según Pita $(2016$, p.122) la carta de navegación de la Educación Ambiental, a través de la política de Educación Ambiental, a partir de la ley 1549 de 2012, por medio de la cual se fortalece la institucionalización de la política nacional de educación ambiental y su incorporación efectiva en el desarrollo territorial.

\section{¿QUÉ ES LA EDUCACIÓN AMBIENTAL?}

Muchos han sido los conceptos que a través del tiempo y la literatura se han establecido con respecto a la educación ambiental, algunos orientados a intereses económicos y políticos, otros culturales y sociales, consensuados a partir de la reunión de líderes mundiales en congresos y seminarios, que han permitido definiciones como la que explicita Guimarães (1995, p.18) establecida en Bogotá en 1976, la cual establece que la Educación ambiental es:

\footnotetext{
"Un instrumento de toma de conciencia del fenómeno de subdesarrollo y de sus implicaciones ambientales, que tienen la responsabilidad de promover estatutos $y$ de crear condiciones para enfrentar las problemáticas eficazmente"
}

Si bien la definición se orienta a la responsabilidad del estado por establecer políticas públicas con referencia al ambiente, sin la consolidación de ciudadanías responsables a partir de la educación, es imposible que estas lleguen a feliz término. Las diferentes vertientes hacia donde se puede dirigir el estudio de la Educación Ambiental son amplias, en educación específicamente, muchas son las actividades que a través del PRAE y otras iniciativas escolares se realizan con el fin de recuperar el papel del hombre como parte de la naturaleza, acciones desligadas que no llegan a convencer al estudiante y cuyo contenido muchas veces policivo tiende a alejar al individuo de su compromiso inherente con el medio ambiente.

El proceso conservacionista al que se han limitado las actividades de la escuela no tiene la repercusión que se espera, por lo tanto, ha de ser la educación 
ambiental un saber que parta desde una epistemología ambiental como "una política del saber que tiene por finalidad dar sustentabilidad a la vida" (LEFF, 2012, p.). Los procesos de preservación de la vida desde un equilibrio dinámico con la muerte como proceso natural, acudiendo al reconocimiento de valores, cosmovisiones, saberes populares y conocimiento científico en cultura con la naturaleza, de tal manera que se recupere la formación del ser, son relevantes en la adquisición de objetivos en torno al saber ambiental, no solo desde la expresión "verde", sino desde la sensibilización y compromiso con la identidad.

Desde esta perspectiva es preciso reconocer la Educación Ambiental crítica como una disciplina "eminentemente interdisciplinar, orientada a la resolución de problemas locales, formadora de ciudadanía, transformadora de valores y actitudes por medio de la construcción de nuevos hábitos y conocimientos" (GUIMARÃES, M.,1995, p.28). De esta manera se propone integrar el conocimiento como proceso emancipatorio, en el cual las relaciones de equidad se den desde el reconocimiento del ser como parte de todo y responsable de ejercer procesos de racionalidad ambiental, mediante los cuales promueva el equilibrio de la naturaleza.

\section{COMPRENDIENDO EL TERRITORIO}

El estudio de caso central de las reflexiones realizadas en este texto, parten del cuestionamiento de los estudiantes de primaria, pertenecientes al Colegio Tomas Carrasquilla I.E.D. ubicado en la ciudad de Bogotá distrito capital, localidad de Barrios Unidos, barrio Simón Bolívar, el cual cuenta con dos sedes contiguas (Sede A: administrativa y bachillerato. Sede B:primaria) y atiende estudiantes de estratos 2 y 3 principalmente de la localidad en que se encuentra ubicada y Suba; su proyecto educativo institucional se titula "Comunicación, Tecnología Y Calidad De Vida" el cual enmarca el proyecto ambiental educativo (PRAE) "Apropiación de valores ambientales en la comunidad tomasina para una cultura del cuidado" esto de acuerdo a las problemáticas ambientales detectadas en la institución, dentro de las que se destacan el mal manejo de las basuras, mal uso de los servicios públicos y la falta de valores y actitudes de conservación de la naturaleza. 
De acuerdo con la contextualización anterior, son varios los proyectos ambientales desarrollados en la institución en el marco del PRAE, como los que se muestran en la imagen 1 y que tienen por objetivo promover valores, enmarcándose así en un corriente ético-moral y conservacionista, esto de acuerdo con Sauve (2005를 $)$ debido a que una misma propuesta puede corresponder a dos o tres corrientes diferentes, según el ángulo bajo el cual es analizada, que desde marco institucional a partir de actividades puntuales impactan a los estudiantes desde primera infancia hasta grado 11.

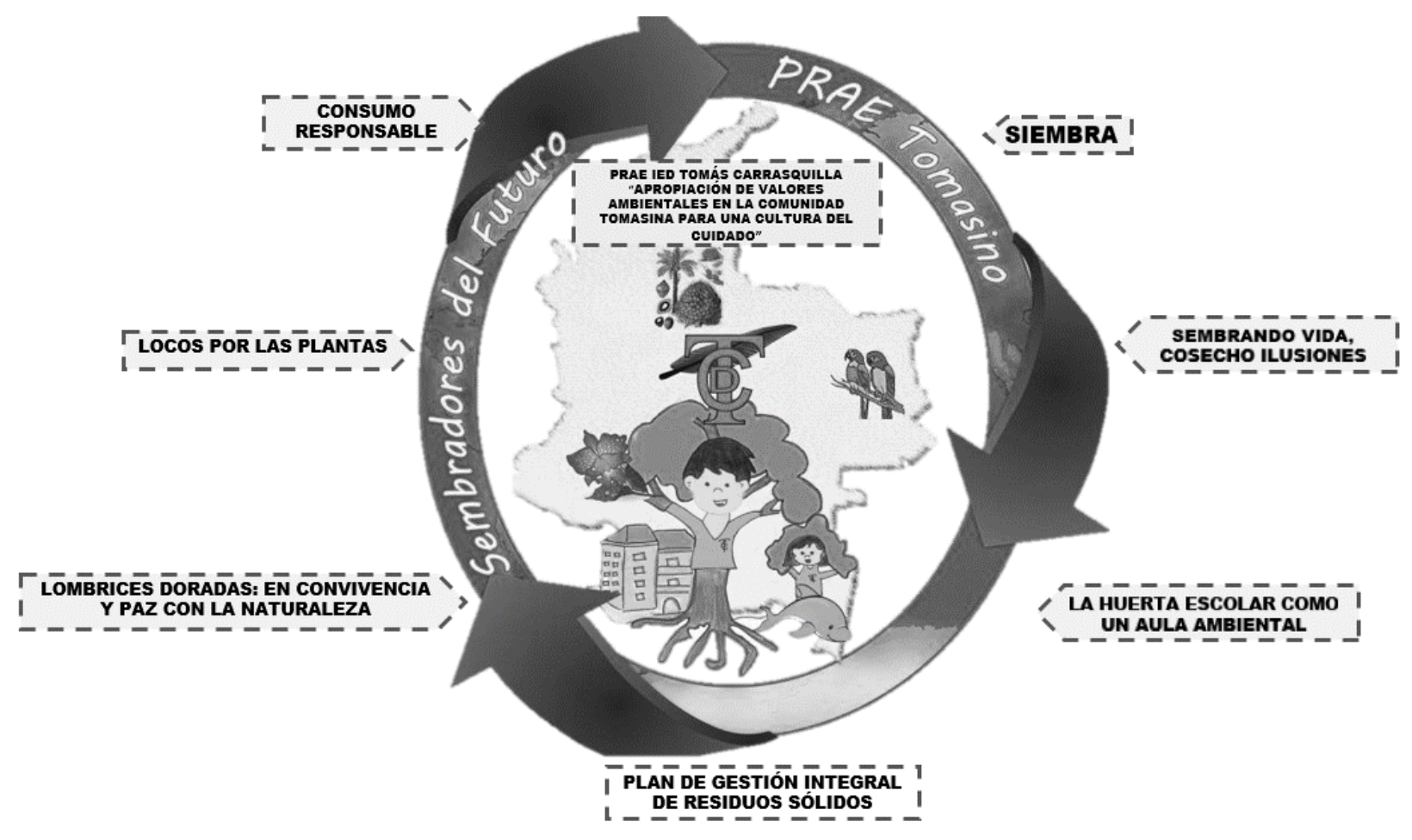

Imagen 1: Logo y esquema PRAE colegio Tomas Carrasquilla I.E.D. Fuente: PRAE Tomas Carrasquilla 2019

Las actividades realizadas desde la escuela son muchas y pretenden involucrar al ser humano como parte de la naturaleza, desde el reconocimiento del lugar y territorio de acuerdo con Escobar (2000, p.68) como una experiencia cotidiana con algún grado de enraizamiento, linderos y conexión con la vida diaria, a pesar de que su identidad sea reconstruida constantemente, esto de acuerdo a la constante movilidad de estudiantes dentro de comunidad educativa de manera 
temporal, que dificulta el desarrollo de una conciencia ambiental que transforme la comunidad y que se visualice a partir de las actitudes de los estudiantes.

Entonces surge la pregunta de ¿Qué hacer para educar ambientalmente y que se vean resultados en la resolución de los conflictos ambientales del colegio?, en este sentido se podría partir de la hipótesis de evitar el descuido en la formación del ser y su desarrollo social, como parte del medio natural, lejos del conservacionismo y partiendo de las esferas de relación propuestas por Sauve, 1999 que se retoman en la imagen 2.

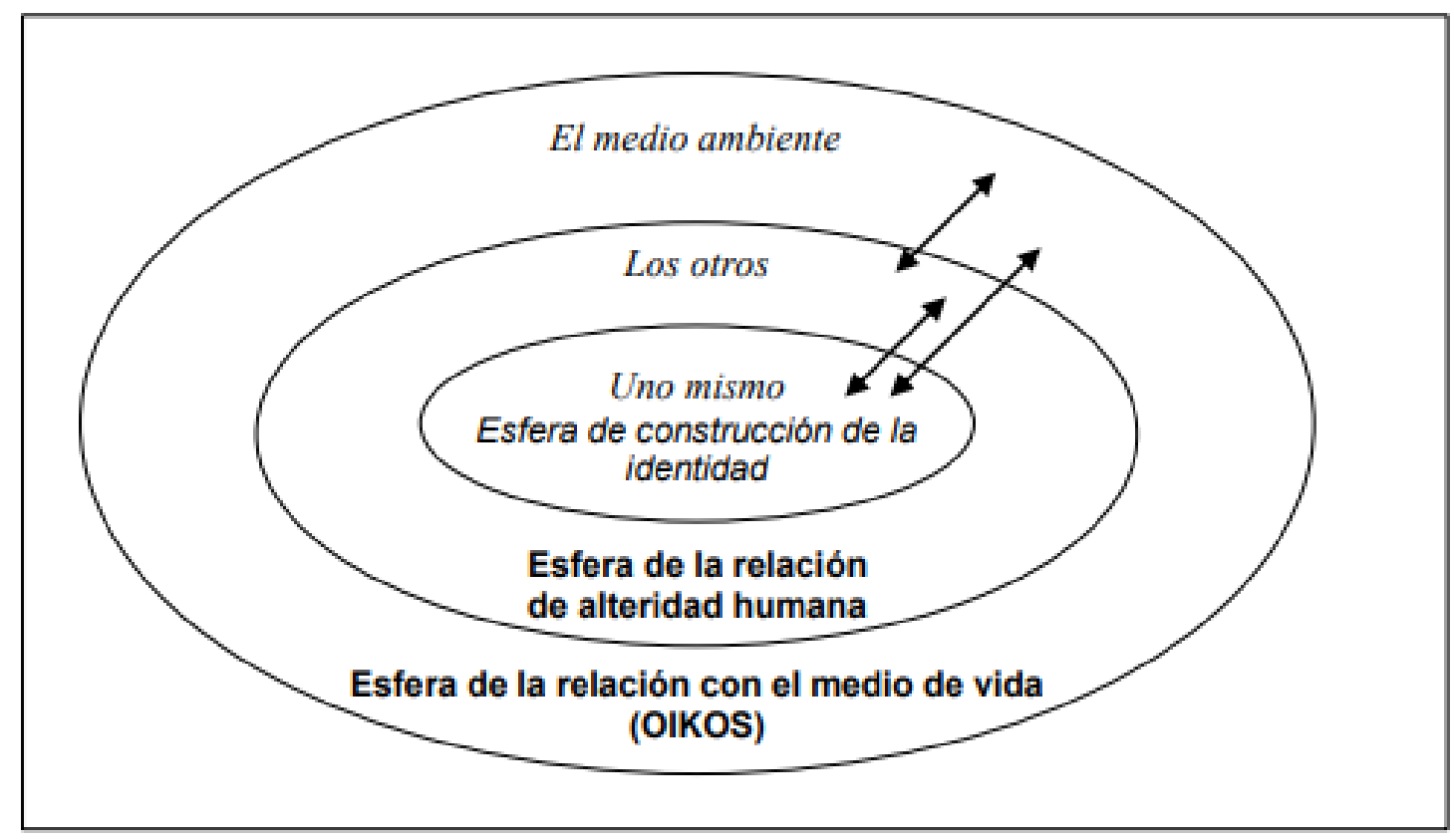

Imagen 2. Esferas interrelacionadas del desarrollo personal y social. Tomado de Sauve, 1999, p.9

Si bien el hombre no es el centro de la naturaleza, sino parte de ella, el hombre tiene las facultades racionales y lógicas, para actuar frente a determinadas situaciones, es por esto por lo que el ser es la esfera principal, según Sauve, 1999:9 desde:

"la confrontación consigo misma (características, capacidades, límites); donde se genera la autonomía y la responsabilidad personal; donde aprendemos a aprender, aprendemos a autodefinirnos y a relacionarnos con las otras esferas" 
Desde esta perspectiva, es a partir del reconocimiento de las fortalezas y debilidades del ser, que se pueden establecer las relaciones con otros y con el ambiente de manera sustentable, de tal forma que la persona actúe de una u otra manera según sus valores y su cambio de visión con respecto al mundo y no porque económicamente represente ganancia destruir el medio en el que coexistimos, por el hecho de ser el hombre quien lo propone, desconociendo las cualidades de la naturaleza y sus dinámicas de justicia ecológica y ambiental, que desde la escuela comienza representada en una nota, un proyecto o la misma institucionalidad de la escuela; en este sentido se estaría realizando educación ambiental para la vida, sin limitaciones como el contexto, pero partiendo de él.

Desde esta perspectiva, los estudiantes plantean la pregunta ¿Por qué la ortiga irrita la piel?, la cual sirve como contexto en la implementación del aprendizaje por proyectos, trabajado desde el ser y desde la resignificación de los saberes populares y ancestrales en el marco científico toda vez que "la biología moderna comienza a darse cuenta de que los llamados" conocimientos tradicionales" pueden ser un complemento bien útil en la conquista científica de la biodiversidad" (ESCOBAR,1999, P.88). En este sentido la educación ambiental parte del niño, su reconocimiento y rol social y ciudadano que lo lleve a la necesidad de conocer para solucionar su conflicto, compartiendo con diferentes actores de la comunidad educativa experiencias que evidencien el uso cultural que se le ha dado a la planta, se desdibuje la idea de que es una planta que no sirve y debe desecharse porque representan invasión en un espacio o por ser utilizada en castigos a menores en el proceso educativo de los ancestros, atendiendo a un dialogo de saberes que les permita comprender los beneficios medicinales de la misma y su preparación (saberes ancestrales), así como sus principales componentes y características taxonómicas, que promueva el cuidado de las plantas y la resignificación de su papel en la naturaleza.

La ortiga mayor o Urtica dioica es una especie de planta aromática, conocida especialmente por su efecto al contacto con la piel, al producir yagas y dolor, desconociendo en muchos casos sus propiedades medicinales que aparecen en rituales indígenas de curación y que ha sido utilizada en diferentes 
investigaciones sobre insecticidas y sustancias nitrificantes en el suelo. Desde estos puntos de vista los niños realizan un proyecto que articule el conocimiento científico (ácidos, tipos de plantas, taxonomía, vitaminas, minerales), conocimiento popular (prácticas culturales) y conocimiento ancestral (Practicas y propiedades medicinales, cosmovisión), partiendo del reconocimiento del ser para contribuir al buen vivir, que desde Gudynas (2011, p.2), parte del cuestionamiento permanente desde las ideas, los discursos y las prácticas.

\section{¿POR QUE ESTE ESTUDIO DE CASO HACE PARTE DE LA EDUCACIÓN AMBIENTAL?}

El proceso de construcción de Educación Ambiental como disciplina, parte de estudios teóricos, filosóficos y experienciales, que fundamentan el desarrollo de propuestas enmarcadas en ella. Si bien los procesos escolares tienen por objetivo la educación, esta a su vez está directamente ligada a la investigación, en cuanto esta "le da su propia identidad, contribuye a comprender su evolución, identificando sus principales problemas, áreas de oportunidad y perspectivas de desarrollo" (Calixto,2012:1023). En este sentido es preciso identificar algunas categorías, de acuerdo con estudios documentales, que evidencian prácticas en donde el ser, el entorno y sus relaciones tienen protagonismo.

De acuerdo con lo anterior Sauve (2005a, p. 17-46) define corriente como una manera general de concebir y de practicar la educación ambiental, desde la cual se han identificado una serie de tradición y otras más recientes que enmarcan una heterogeneidad de características y que se condensan de acuerdo con el análisis desarrollado de ellas. Entre las corrientes caracterizadas por medio de la cartografía en Educación ambiental se encuentran las mencionadas en la tabla 2, las cuales evidencian una estrategia que combate algunas diferencias dialécticas en el discurso del educador ambiental y que en muchas ocasiones desvía el punto de discusión del fondo de los problemas. 


\begin{tabular}{|c|c|c|}
\hline $\begin{array}{l}\text { TIPO DE } \\
\text { CORRIENTE }\end{array}$ & CORRIENTE & CARACTERISTICA PRINCIPAL \\
\hline \multirow{7}{*}{ Tradicional } & Naturalista & $\begin{array}{l}\text { Tiene un enfoque cognitivo, experiencial, } \\
\text { afectivo, experiencial y artístico, en las } \\
\text { relaciones humano-ambiente, en donde la } \\
\text { naturaleza tiene un valor intrínseco. }\end{array}$ \\
\hline & Conservacionista & $\begin{array}{l}\text { Centrada en la conservación de los recursos } \\
\text { naturales como medio para proveer } \\
\text { alimentos, medicina, vestido, etc. }\end{array}$ \\
\hline & $\begin{array}{l}\text { Resolución de } \\
\text { problemas } \\
\text { actuales }\end{array}$ & $\begin{array}{l}\text { Enfocada en el reconocimiento y resolución } \\
\text { de problemas ambientales, en donde el } \\
\text { ambiente se constituye como conjunto de } \\
\text { problemas. }\end{array}$ \\
\hline & Sistémica & $\begin{array}{l}\text { Reconoce las interrelaciones de los } \\
\text { elementos que componen el ambiente, como } \\
\text { síntesis de la realidad. }\end{array}$ \\
\hline & De la ciencia & $\begin{array}{l}\text { Se basa en el tratamiento de las realidades y } \\
\text { problemas ambientales con rigor, a partir de } \\
\text { relaciones causa-efecto, desde el proceso } \\
\text { científico. }\end{array}$ \\
\hline & Humanista & $\begin{array}{l}\text { Enfocada en la dimensión humana del medio } \\
\text { ambiente desde la relación naturaleza-cultura, } \\
\text { partiendo del medio ambiente como } \\
\text { patrimonio. }\end{array}$ \\
\hline & Moral-Ética & $\begin{array}{l}\text { Centrada en el desarrollo de valores } \\
\text { ambientales, eco-civismo, y la construcción } \\
\text { de la ética para la vida cotidiana. }\end{array}$ \\
\hline Emergente & Holística & $\begin{array}{l}\text { Tiene un enfoque analítico y racional de las } \\
\text { realidades ambientales desde la apropiación } \\
\text { del lugar para proveer la plenitud de cada ser }\end{array}$ \\
\hline
\end{tabular}




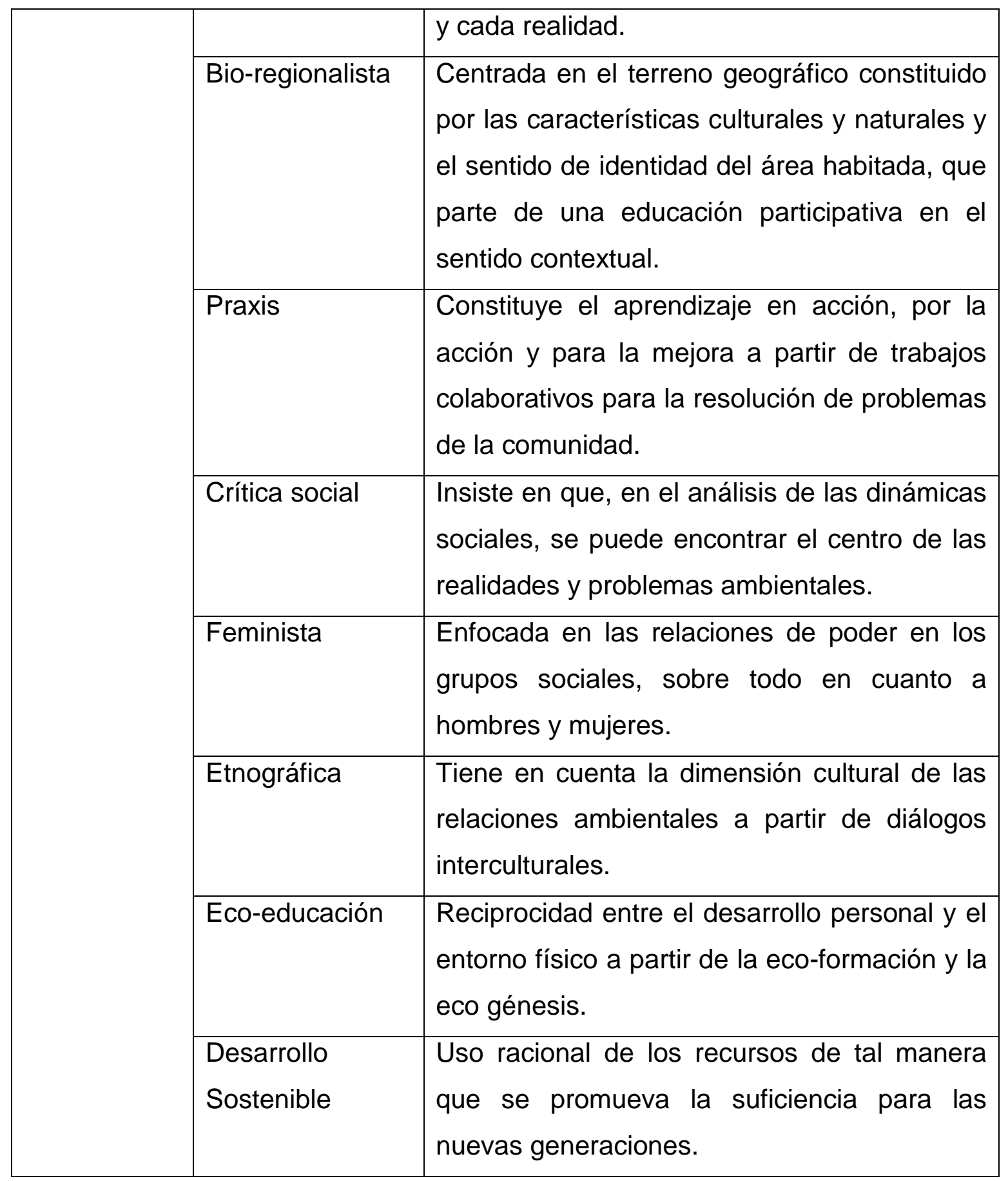

Tabla No. 2. Adaptación según Sauve, 2005b, p. 11-32. Fuente: Creación Propia.

Las corrientes en Educación Ambiental y sus principales características, como fundamento de la propuesta a analizar, rescata la Corriente práctica en cuanto "No se trata de desarrollar a priori los conocimientos y las habilidades en vista de una eventual acción, sino de ponerse inmediatamente en situación de acción y de 
aprender a través del proyecto por y para ese proyecto" (SAUVE, 2005ª p.33). De acuerdo con lo anterior, el proyecto escolar deja de lado la adquisición de contenidos por memorización y lleva al estudiante a la práctica, ya que fue desde allí, y su experiencia al tocar la planta, que se generan preguntas que desde su visión constituyen una problemática, la cual no puede ser resuelta solamente desde la ciencia, sino que cruza las fronteras invisibles de la ética, la cultura, el conocimiento ancestral, la política y la educación, la relación de cada uno consigo mismo y como se puede interactuar con el ambiente para privilegiar la adquisición de saberes, que desde la práctica, tendrán repercusión en la educación para la vida.

El desarrollo teórico de la Educación Ambiental, no solo la ha fundamentado, sino que deja entrever una serie de categorías de análisis como la transdisciplinariedad, ciudadanía, historia de vida, Pertenecer, cultura y conocimiento, ser social y saberes populares, entre los más importantes, desde los cuales se pueden establecer relaciones vivenciales de la EA. Desde la perspectiva propia del estudio de caso central de este texto, se rescatan los saberes populares, como base para el desarrollo de una educación ambiental crítica y transformadora en la cual no se descuide el saber científico, sino que se propenda por mantener una "preocupación concreta en estimular el debate y el diálogo entre ciencias y cultura popular, redefiniendo objetos de estudio y saberes" (LOUREIRO, 2006, p.134). Lo anterior como base de una formación ciudadana a partir de la resignificación del ser no solo como sujeto que exige sus derechos sino para "ser sujetos sociales activos, agentes de la existencia de sus derechos y constructores de su propia historia, en suma, agentes políticos" (NEPOMUCENO, 2016, p.65).

En este sentido, la construcción de ciudadanos críticos socioambientales, parte de la construcción del ser en sus diferentes dimensiones, a partir del dialogo de saberes culturales y científicos que llevan a que el individuo reconozca su pertenencia en el territorio ser y escuela, que desencadena su "capacidad de entender y discutir el contexto local para resignificar teorías implícitas sobre la biorregión y así llegar a construir un sentimiento de pertenencia a la misma" (COPELLO,2008, p.24). En este sentido, la propuesta esta enmarcada en la 
transformación del territorio a partir del ser y sus relaciones con el mundo al que pertenece.

\section{CONSIDERACIONES FINALES}

Si bien cada una de las practicas realizadas en el aula, parten de las necesidades del contexto y constituyen pequeños peldaños para una verdadera transformación ambiental, es importante reconocer al sujeto no solo como el responsable del caos, sino también como el sujeto de oportunidad que a través de la racionalidad ambiental y el dialogo de saberes, puede desarrollar prácticas ambientales sustentables, realmente amigables con el planeta y que en relación con otros, generen aquellos impactos utópicos, que son característicos de la educación ambiental.

Cabe resaltar que el proyecto bajo el cual se desarrolla el estudio de caso está enmarcado en el desarrollo de habilidades de pensamiento crítico desde la educación ambiental, aplicando el aprendizaje basado en proyectos con estudiantes de quinto grado de educación primaria, que, enmarcado en un problema ambiental de interés, promueve la participación, toma de conciencia y decisiones en contexto, a partir de la evaluación de información, análisis, interpretación, inferencias, explicación y autorregulación del ser, como habilidades primordiales de un ciudadano crítico, consiente de su papel en la naturaleza, el cual busca la transformación del territorio al que pertenece a partir de una práctica científica y la resignificación del saber popular.

La educación ambiental Critica, que desde el Loureiro (2006, p.141) se basa en el desarrollo de proyectos que metodológicamente van más allá del aula de clase, al ser una práctica cotidiana, que necesita la formación emancipatoria, ciudadana y política de los seres. La educación Ambiental desde este paradigma transformador debe estar enmarcada en el pensamiento crítico e innovador, mediante la educación formal o no formal que promueva la construcción de sociedades a partir de la dialéctica, la cual permite formular visiones del mundo, que parten de los sujetos que 
pertenecen a ella y los cuales pueden modificar o no, el destino socioambiental de su territorio. 


\section{REFERENCIAS}

Calixto Flores, R. (2012). Investigación en educación ambiental. Revista mexicana de investigación educativa, 17(55), 1019-1033.

Copello, M. I., Cousin, C., \& Aguiar, C. (2008). Algunas propuestas de Educación Ambiental en la escuela.

De Educación, L. G. (1994). Ley 115 de 1994. Constitución Política de Colombia.

Escobar, A. (1999). El final del salvaje: naturaleza, cultura y política en la antropología contemporánea (Vol. 3). Cerec.

Escobar, Arturo. 2000. El lugar de la naturaleza y la naturaleza del lugar: ¿globalización o postdesarrollo? En: La colonialidad del saber: eurocentrismo y ciencias sociales. Perspectivas Latinoamericanas. Edgardo Lander (comp.) CLACSO. Buenos Aires, Argentina. En línea: http://bibliotecavirtual.clacso.org.ar/ar/libros/lander/escobar.rtf

García, J., \& Ferrandis, I. F. (1990). Revisión histórica del concepto de Educación Ambiental. Didáctica de las Ciencias Experimentales y Sociales.

Gaudiano, E. G. (2001). Otra lectura a la historia de la educación ambiental en América Latina y el Caribe. Desenvolvimento e Meio Ambiente, 3.

Gudynas, E. (2011). Buen Vivir: Germinando alternativas al desarrollo. América Latina en movimiento, 462, 1-20.

Guimarães, M. (1995). Dimensao Ambiental Na Educaçao (a). Papirus Editora.

Leff, E. (2012). Aventuras de la epistemología ambiental: de la articulación de ciencias al diálogo de saberes. Siglo XXI.

Loureiro, C. F. B. (2006). Complexidade e dialética: contribuições à práxis política e emancipatória em educação ambiental. Educ. Soc., Campinas, 27(94), 131-152.

MEN, M. (2002). Política nacional de educación ambiental sina. Bogotá. Colombia, 31.

Nepomuceno, A. L. D. O., \& Guimarães, M. (2016). Caminhos da práxis participativa à construção da cidadania socioambiental. Revista Ambiente \& Educação (Dossiê Temático Fundamentos da Educação Ambiental).

Pita-Morales, L. A. (2016). Línea de tiempo: educación ambiental en Colombia. Praxis, 118-125. 
Sauvé, L. (1999). La educación ambiental entre la modernidad y la posmodernidad: en busca de un marco educativo de referencia integrador. Tópicos, 1(2), 7-27.

Sauvé, L. (2005a). Uma cartografia das corrientes em educaçao ambiental. (p. 1746). In Sato, M. et Carvalho, I. (Dir.). Educação ambiental - Pesquisa e desafios. Porto Alegre: Artmed.

Sauvé, L. (2005b). Currents in Environmental Education: Mapping a Complex and Evolving Pedagogical Field. Canadian Journal of Environmental Education, 10(1), 1137.

Teitelbaum, A. (1978). El papel de la educación ambiental en América Latina (No. 344.046 T4). 